\title{
ПРИМЕНЕНИЕ ПОЛИМЕРНЫХ КОЛЛОИДНЫХ НОСИТЕЛЕЙ ДЛЯ ТАРГЕТНОЙ ДОСТАВКИ МОЗГОВОГО ТРОФИЧЕСКОГО ФАКТОРА ЧЕРЕЗ ГЕМАТО- ЭНЦЕФАЛИЧЕСКИЙ БАРЬЕР ПРИ ЭКСПЕРИМЕНТАЛЬНОМ ПАРКИНСОНИЗМЕ
}

М. Ю. Капитонова' ${ }^{1}$ Р. Н. Аляутдин ${ }^{2 凶}$, Р. В. А. Л. Ван Шазли , М. Н. К. Нор-Ашикин ${ }^{3}$, А. Ахмад ${ }^{3}$, С. Норита ${ }^{3}$, С. С. Дыдыкин

Факультет медицины и здравоохранения, Университет Малайзии Саравак (ЮНИМАС), Кота-Самарахан, Саравак, Малайзия

Управление экспертизы безопасности лекарственных средств, Научный центр экспертизы средств медицинского применения, Москва

Медицинский факультет, Университет технологии МАРА, Сунгай Було, Селангор, Малайзия

${ }^{4}$ Кафедра оперативной хирургии и топографической анатомии, Сеченовский Первый Московский государственный медицинский университет, Москва

Болезнь Паркинсона - одно из распространенных возрастных моторных нейродегенеративных заболеваний, при котором дегенерация дофаминергических нейронов считается патогномоничной для развития моторной дисфункции. Мозговой трофический фактор (БДНФ) считается ключевым регулятором нейронной пластичности и, являясь крупной молекулой, не проходит через гемато-энцесалический барьер (ГЭБ). Синтетические полимерные наночастицы (НЧ), покрытые сурфактантом, обеспечивают феномен «троянского коня» и позволяют доставлять БДНФ в ткани головного мозга. Целью работы было оценить нейропротективное действие БДНФ, сорбированного на полилактидных НЧ, в общепринятой модели паркинсонизма, вызванного применением МФТП. Для моделирования синдрома паркинсонизма использовали нейротоксин 1-метил-4-сенил-1,2,3,6-тетрагидропиридин (МФТП), который внутрибрюшинно вводили мышам линии C57BL/6 с последующим внутривенным введением физраствора (1-я группа мышей), раствора БДНФ (2-я группа), БДНФ, сорбированного на полилактидных НЧ (3-я группа), и БДНФ, сорбированного на полилактидных НЧ, покрытых сурфактантом (4-я группа). Через 90 мин, 24 ч, 72 ч и 7 суток оценивали проявления паркинсонизма в поведенческих тестах открытого поля, на рота-роде, по интенсивности тремора, изменению длины тела и шага животных. По окончании эксперимента головной мозг извлекали для гистологической оценки изменений в стриапаллидарной системе и среднем мозге, а также для определения концентрации БДНФ в тканях головного мозга. Результаты показали, что БДНФ, сорбированный на полилактидных НЧ, покрытых сурфактаном, существенно уменьшал ригидность скелетных мышц, олигокинезию и тремор, а также достоверно повышал концентрацию БДНФ в тканях головного мозга.

Ключевые слова: мозговой трофический фактор, паркинсонизм, наночастицы, гемато-энцефалический барьер, иммуноферментый анализ

Финансирование: исследование выполнено в рамках гранта 600-RMI/RAGS 5/3 (92/2013) Университета технологии MAPA, Селангор, Малайзия.

$\triangle$ Для корреспонденции: Ренад Николаевич Аляутдин

1-й Волоколамский проезд, д. 10, корп. 4, г. Москва, 119876; alyautdun@mail.ru

Статья получена: 09.07.18 Статья принята к печати: 20.08.18

DOI: $10.24075 /$ vrgmu.2018.072

\section{APPLICATION OF NANOSCALE POLYMER COLLOID CARRIERS FOR TARGETED DELIVERY OF THE BRAIN-DERIVED NEUROTROPHIC FACTOR THROUGH THE BLOOD-BRAIN BARRIER IN EXPERIMENTAL PARKINSONISM}

Kapitonova MYu', Alyautdin RN²凶, Wan-Syazli RWAL ${ }^{3}$, Nor-Ashikin MNK ${ }^{3}$, Ahmad A ${ }^{3}$, Norita S ${ }^{3}$, Dydykin SS ${ }^{4}$

${ }^{1}$ Faculty of Medicine and Health Sciences, University Malaysia Sarawak (UNIMAS), Kota Samarahan, Sarawak, Malaysia

${ }^{2}$ Department for Expertise of Medicinal Products safety, Scientific Centre for Expert Evaluation of Medicinal Products, Moscow

${ }^{3}$ Faculty of Medicine, University Teknologi MARA, Sungai Buloh, Selangor, Malaysia

${ }^{4}$ Department of Operative Surgery and Topographic Anatomy, Sechenov First Moscow State Medical University, Moscow

Parkinson disease is one of the common age-related motor neurodegenerative diseases, in which dopamine neurons degeneration is considered to be pathognomic for the development of motor disfunction. Brain-derived neurotrophic factor (BDNF) is a member of the neurotrophin family, which is considered to be a key regulator of neuronal plasticity. BDNF, being a large molecule, does not pass through the blood-brain barrier (BBB). Synthetic polymer nanoparticles (NP), covered by surfactant, provide the phenomenon of "Trojan hoarse" and enable BDNF to penetrate into the brain tissue. For modelling of parkinsonism we used an intraperitoneal (i.p.) injection of neurotoxin 1-methyl-4-phenyl-1,2,3,6-tetrahydropyridine (MPTP) which was injected to the C57BL/6 mice with subsequest treatment with normal saline (group 1), BDNF (group 2), nanoparticulate BDNF (group 3) and surfactant-coated nanoparticulate BDNF (group 4). After 90 min, 24 hours, 72 hours and 7 days manifestations of parkinsonism were evaluated using behavioural tests of open field, rota-rod, assessment of the tremor, length of the body and pace. At the end of experiment the brain was sampled for histological evaluation of changes in the striatum and midbrain and concentration of BDNF in the brain tissues. The results of the experiments demonstrated that nanoparticulate BDNF covered with surfactant significanltly reduced rigidity of the skeletal muscles, oligokinesia and tremor, and also significantly increased BDNF concentration in the brain tissues.

Keywords: brain-derived neurotrophic factor, parkinsonism, nanoparticles, blood-brain barrier, ELISA

Funding: this work was supported by the grant 600-RMI/RAGS 5/3 (92/2013) of the Universiti Teknologi MARA (UiTM), Selangor, Malaysia.

$\square$ Correspondence should be addressed: Renad N. Alayutdin

1 Volokolamskiy Proezd 10, bl. 4, Moscow, 119876; alyautdun@mail.ru

Received: 09.07.18 Accepted: 20.08.18

DOI: $10.24075 /$ brsmu.2018.072 
Повышение эффективности действия лекарственных веществ при снижении их токсичности и выраженности побочных эффектов является основным направлением современной фармакологии. Анализ современной литературы позволил выделить два способа решения поставленной задачи: 1) увеличение избирательности действия лекарственных веществ; 2) создание более высокой концентрации препаратов в области структурмишеней, в частности в центральной нервной системе (ЦНС), за счет направленного транспорта лекарств с помощью специфических носителей [1, 2]. Если для применения первого способа основным ограничением является присутствие одинаковых по чувствительности мишеней в различных структурах организма (вследствие чего искомая избирательность не достижима), то при применении второго ограничением будет токсичность компонентов системы дистанционной доставки лекарств, но при этом большим преимуществом окажется высокая избирательность. Кроме того, имеется ряд потенциально важных препаратов, дистанционная и избирательная доставка которых просто необходимы (например, фактор некроза опухоли). Существенным препятствием для проникновения в мозг многих лекарственных веществ является наличие гемато-энцефалического барьера (ГЭБ). Плотные контакты между эндотелиоцитами капилляров головного мозга служат препятствием для проникновения в мозг многих высокомолекулярных и гидрофильных веществ, а наличие Р-гликопротеина затрудняет проникновение ряда липофильных соединений [3, 4]. Таким образом, наличие ГЭБ ограничивает возможности медикаментозной коррекции нейродегенеративных заболеваний, опухолей мозга и других нарушений ЦНС.

Многие пептиды и белки служат регуляторами различных функций ЦНС, В связи с чем Они потенциально могут быть использованы при состояниях, сопровождающихся нейродегенерацией [5, 6]. Существенным фактором, лимитирующим клиническое применение веществ пептидной природы, являются низкая способность проникать через ГЭБ и подверженность ферментативной инактивации. Полимерные коллоидные системы способны обеспечивать транспорт лекарственных препаратов в мозг, в том числе соединений белковой структуры [7].

Для создания модели паркинсонизма был использован МФТП - соединение, проникающее через ГЭБ и образующее в головном мозге метаболит, который блокирует тирозингидроксилазу, что в итоге приводит к десициту дофамина в черной субстанции [8]. В нашей работе с целью оценки возможности доставки и получения нейропротекторного действия в модели паркинсонизма для таргетной доставки БДНФ были использованы биодеградируемые полилактидные наночастицы (НЧ), покрытые сурфактантом.

Целью настоящего исследования было оценить нейропротективное действие БДНФ, сорбированного на полилактидных НЧ, в общепринятой модели паркинсонизма, вызванного применением МФТП.

\section{МАТЕРИАЛЫ И МЕТОДЫ}

Эксперименты проводили на мышах линии C57BL/6 самцах массой 20-25 г (виварий «LACU» Института медицинской молекулярной биотехнологии (IMMB), Университета технологии МАРА; Малайзия). Протокол исследования прошел экспертизу этического комитета
«UiTM Care» при Университете технологии MAPA (протокол № 122/2015 от 6 ноября 2015).

Все животные проходили период предварительной адаптации к условиям лаборатории в течение одной недели до начала эксперимента. Каждую мышь использовали только один раз. Животных содержали в клетках из нержавеющей стали по 4 мыши в каждой клетке в условиях свободного доступа к корму и воде при температуре $20-22{ }^{\circ} \mathrm{C}$ и влажности 50-60\%, при следующем световом режиме: 12 ч свет/12 ч темнота. Для минимизации возможных сбоев циркадианных ритмов и исключения хронофармакологических влияний введение лекарственных препаратов проводили в утренние часы. Все эксперименты проводили в первую половину дня. Каждая экспериментальная группа составляла 6-8 мышей.

Паркинсонизм моделировали введением нейротоксина МФТП внутрибрюшинно [9]. Оценку основных экстрапирамидных нарушений проводили согласно методикам, описанным ниже, сразу после введения МФТП на протяжении первых 45 мин, после чего животным, предварительно разделенным на 4 группы, внутривенно вводили в латеральную хвостовую вену 0,2 мл лекарственной смеси одного из составов: 1-я группа физраствор; 2-я группа - БДНФ; 3-я группа - БДНФ + НЧ; 4-я группа - БДНФ + НЧ + сурфактант (полоксамер 188). Наблюдения и поведенческие тесты проводили через 90 мин, 24 ч, 72 ч и 7 дней после введения нейротоксина.

По окончании последнего теста на 8-й день эксперимента животных выводили из эксперимента путем декапитациии. Головной мозг извлекали, левое полушарие фиксировали в 10\%-м формалине для последующего гистологического исследования, а правое полушарие замораживали жидким азотом при $-70{ }^{\circ} \mathrm{C}$ для последующего определения содержания БДНФ в тканях головного мозга методом иммуноферментного анализа.

\section{Вещества и материалы}

Для моделирования паркинсонизма использовали: официнальный физиологический раствор (0,9\%-й раствор хлорида натрия) (Sigma-Aldrich; США); 1-метил-4-фенил1,2,3,6-тетрагидропиридина (1-Methyl-4-phenyl-1,2,3,6tetra hydropyridine hydrochloride powder, Sigma-Aldrich; США).

При развитии паркинсонизма использовали: осицинальный физиологический раствор (0,9\%-й раствор хлорида натрия) (Sigma-Aldrich; США); 10\%-й раствор полоксамера 188 (Poloxamer 188) (Sigma-Aldrich; CША), рекомбинантный человеческий БДНФ (Recombinant human BDNF) (Raybiotech; США); полилактидные HЧ среднего диаметра 200 нм (Degradex TM PLGA (MW 45-75 KD) nanospheres) (Phosphorex, Inc.; CШA).

Для проведения иммуноферментного анализа использовали: набор реактивов для иммуноферментного анализа БДНФ у мышей и крыс (Total BDNF Immunoassay; Catalog Number DBNTO0) (Quantikine ${ }^{\circledR}$ ELISA, R\&D Systems; США), фоссратный буфер (Sigma- Aldrich; США) и лизисбycpep 17 (Lysis Buffer 17, catalog \#895943) (R\&D system, Abingdon; UK).

\section{Моделирование паркинсонизма}

Раствор МФТП в физиологическом растворе вводили экспериментальным животным внутрибрюшинно в дозе $30 \mathrm{M} \Gamma / \mathrm{K} \Gamma$. 


\section{Получение БДНФ, сорбированного на наночастицах}

Лиофилизированный порошок БДНФ (50 мкг) растворяли в 1 мл изотонического раствора натрия хлорида. Раствор БДНФ объединяли с суспензией НЧ (40 мг НЧ в 1 мл физраствора) и инкубировали при пониженной температуре $\left(0-4{ }^{\circ} \mathrm{C}\right)$ в течение 3 ч, проводили сонисрикацию на ультразвуковом дезинтеграторе 15 мин при мощности 60 Вт с последующим перемешиванием на магнитной мешалке в течение 3 ч при скорости 300 об./мин.

\section{Приготовление суспензии наночастиц}

Лиофилизированный порошок (40 мг) НЧ, содержащий 23,53 мг полимера, диспергировали в 1 мл изотонического раствора хлорида натрия до получения однородной суспензии молочно-белого цвета. Проводили сонификацию на ультразвуковом дезинтеграторе 15 мин при мощности 60 Вт с последующим перемешиванием на магнитной мешалке в течение 3 ч при скорости 300 об./мин.

\section{Приготовление суспензии наночастиц с БДНФ и сурфактантом}

Для приготовления суспензии НЧ с БДНФ и сурфактантом к суспензии БДНФ, сорбированного на полилактидных H4, добавляли 0,2 мл 10\%-го раствора полоксамера 188 и перемешивали на магнитной мешалке. В результате получали 2 мл 1,18\%-й суспензии Н4, покрытых полоксамером и содержащих 50 мкг БДНФ (5 мкг БДНФ в 0,2 мл суспензии). В этом случае для сохранения общего объема раствора 2 мл НЧ и БДНФ растворяли не в 1 мл, а в 0,9 мл физраствора.

Физраствор или БДНФ, или БДНФ, сорбированный на полилактидных НЧ, или БДНФ, сорбированный на полилактидных НЧ с полоксамером, в объеме 0,2 мл вводили животным с 1-й по 4-ю группу соответственно в латеральную хвостовую вену через 45 мин после введения нейротоксина.

Эфффективность исследуемых веществ оценивали по их способности ослаблять основные проявления паркинсонизма, вызываемого введением МФТП (олигокинезии, ригидности и тремора), а также регистрировали наличие и выраженность слюнотечения, пилоэрекции, ретропульсии, нарушений дыхания.

\section{Методика оценки ригидности}

Для количественной оценки ригидности мышц туловища использовали симптом «горбатости», выраженность которого зависит от мышечной ригидности и определяется по укорочению расстояния от шеи до основания хвоста за счет сгорбленности животного. Длину тела от основания ушей до основания хвоста измеряли линейкой по видеоизображению в открытом поле. Передние и задние лапки животных окрашивали различными специальными красителями. Определяли расстояние между следами от передних и задних лапок, оставшимися на ленте. Ротарод-тест проводили на ротароде марки ENV-576 (Med Associates; США) в ускоряющемся режиме N5 (220 об./Мин).

\section{Методика регистрации тремора}

Тремор оценивали по его выраженности в баллах, а также по количеству в процентах животных с тремором в группе.
По локализации и амплитуде тремор оценивали в баллах: 0 - отсутствие, 1 - локальный мелкоамплитудный тремор головы, передних лап или хвоста, 2 - локальный среднеамплитудный тремор, 3 - генерализованный мелко- или среднеамплитудный тремор всего тела [10].

\section{Методика оценки олигокинезии в тесте открытого поля}

При паркинсонизме, вызываемом нейротоксином, наблюдается не только уменьшение количества движений, но и нарушение их качественной структуры. Понятие "олигокинезия" включает уменьшение количества и качества локомоторной активности. «Открытое поле» представляло собой белую квадратную арену с белыми бортами высотой 50 см. Все пространство арены равномерно разделили на 64 одинаковых квадратов размером $10 \times 10$ см. Арену протирали влажной губкой после тестирования каждого животного.

Животное помещали в центр арены сразу после введения МФТП и затем через 90 мин, 24 ч, 72 ч и 7 дней после введения нейротоксина регистрировали в течение 3 мин число горизонтальных и вертикальных движений (стоек). За единицу перемещения при визуальной регистрации поведения был принят один пересеченный квадрат. Вертикальную двигательную активность животных в открытом поле определяли двумя видами стоек: задние лапы животного остаются на полу арены, а передние или упираются в стенку поля, или остаются на весу. Обсчет результатов вели по общей вертикальной двигательной активности.

\section{Иммуноферментный анализ}

Для проведения иммуноферментного анализа использовали приборы: микроплатовый ридер Victor'T X, способный измерять поглощение при 450 нм (Perkin Elmer; США); тканевой гомогенизатор Omni-Ruptor 4000 (OMNI International Inc.; США); горизонтальный орбитальный шейкер со скоростью5 500+/-50 об./мин (VISION Scientific Co. Ltd; Южная Корея).

Левое полушарие головного мозга промывали фосфатным буфером и гомогенизировали с помощью тканевого гомогенизатора в 500 мкл фосфатного буфера. Такое же количество лизис-буфера 17 добавляли к тканям и оставляли лизироваться на 30 мин при комнатной температуре при легком встряхивании. Детрит удаляли центрифугированием при 10000 g, при температуре $4^{\circ} \mathrm{C}$, надосадочную жидкость отделяли и оставляли при температуре $-80{ }^{\circ} \mathrm{C}$ до проведения анализа. Уровень содержания БДНФ определяли с помощью набора для иммуноферментного анализа (R\&D Systems, Abingdon; UK) в соответствии с протоколом производителя с использованием микроплатового ридера Victor $^{\mathrm{TM}} \mathrm{X}$ (Perkin Elmer; США) при длине волны 450 нм. Оптическую плотность образца при 450 нм соотносили с длиной волны 570 нм во избежание погрешности платы. Результаты выражали в пг/мг общего белка.

\section{Статистическая обработка результатов}

Полученные данные обрабатывали с помощью программы Excel c вычислением средней арифметической, среднеквадратического отклонения, ошибки репрезентативности, t-критерия Стьюдента. Различия считали достоверными при $p<0,05$. 


\section{РЕЗУЛЬТАТЫ ИССЛЕДОВАНИЯ}

Уже через 2 мин после введения МПТФ у мышей всех четырех групп появлялись симптомы паркинсонизма: вначале генерализованный тремор, мелко- или среднеамплитудный; в течение последующих 3-5 мин ретропульсия и пилоэрекция. Пилоэрекция была настолько выраженной, что у большинства мышей между волосками черного покрова начинала просвечивать белая кожа, особенно заметная в области задней поверхности шеи. В течение последующих 10-15 мин на первый план выходили признаки ригидности мышц: походка становилась неустойчивой, уменьшалась длина шага, появлялись ротационные движения, укорачивалась длина тела и появлялся характерный горб в торако-люмбарном отделе позвоночника. Через 1,5 ч от начала эксперимента (45 мин после введения исследуемых веществ) у мышей 1-й группы сохранялся тремор и полностью отсутствовали задние стойки, в то время как во 2-й и 3-й группах тремор уменьшался и появлялись единичные задние стойки, а в 4-й группе тремор практически исчезал и задние стойки появлялись значительно чаще. У животных 4-й группы восстанавливались длина шага и способность вращаться на ротароде, а также возрастало количество пересеченных квадратов. У животных 1-3-й групп длина шага и способность вращаться на ротароде практически не изменялись; количество пересеченных квадратов и длина тела мало изменялись в 1-й и 2-й группах, но намечалась тенденция к их увеличению в 3-й группе. Статистический анализ показал, что по всем перечисленным показателям достоверная положительная динамика отмечалась только у мышей 4-й группы, причем при сравнении с каждой из остальных групп, в то время как 1-я, 2-я и 3-я группы различались между собой по данным параметрам недостоверно (рис. 1-3).

Через 24 и 72 ч от начала эксперимента у животных по количеству пересеченных квадратов, длине тела и шага, и интенсивности тремора, восстановлению длины тела и способности вращаться на ротароде тенденции, отмеченные на предыдущем сроке наблюдения, сохранялись, различаясь лишь уровнем достоверности (от $p<0,05$ до $p<0,01)$. Через 7 дней у животных 3-й и 4-й групп наблюдали полное отсутствие тремора, и хотя у животных 1-й и 2-й групп имели место отдельные подрагивания тела, данный показатель варьировал от особи к особи, в связи с чем достоверных отличий по данному показателю между группами не выявлено. Уменьшение длины тела также продолжало сокращаться во всех группах, но различия по данному параметру между группами были недостоверны. По остальным четырем критериям попрежнему достоверное улучшение отмечалось лишь у 4-й группы по сравнению со всеми остальными группами.

При введении раствора БДНФ (таблица) увеличение содержания его концентрации в головном мозге было недостоверно выше (на 11\%), чем при введении физраствора $(p>$ 0,05). При введении БДНФ, сорбированного на НЧ, оно достоверно увеличивалось на $16 \%(p<0,05)$ по сравнению с группой, получавшей физраствор, а при введении БДНФ, сорбированного на НЧ с полоксамером - на 20\% ( $<$ 0,01). По сравнению с раствором БДНФ, при введении БДНФ, сорбированного на НЧ, и БДНФ, сорбированного на НЧ с полоксамером,

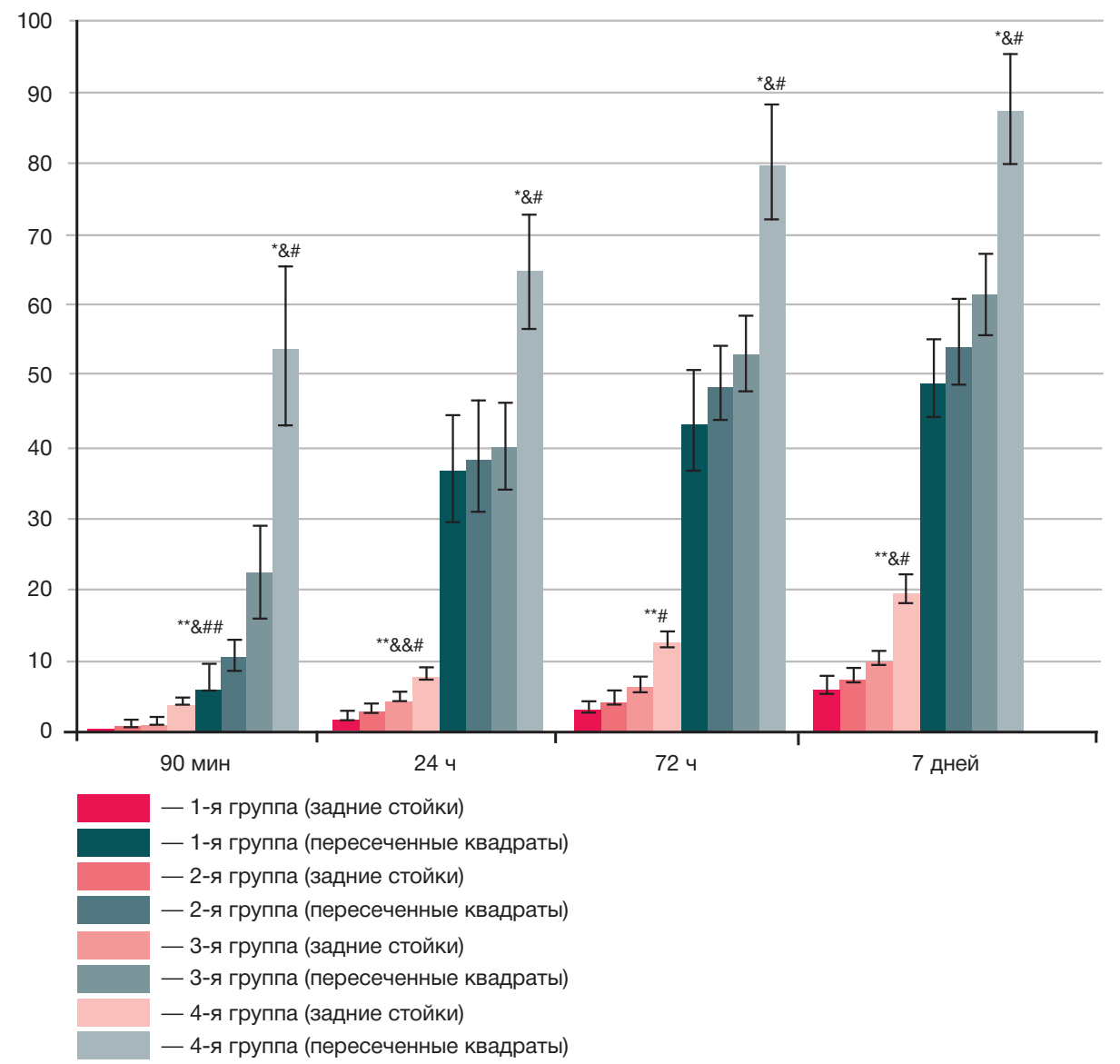

Рис. 1. Результаты теста «открытое поле» у контрольных и экспериментальных мышей в модели паркинсонизма (m \pm SEM). * $-p<0,05$ при сравнении с 1-й группой, ${ }^{* *}-p<0,01$ при сравнении с 1-й группой, \& - p < 0,05 при сравнении со 2-й группой, \&\& - $p<0,01$ при сравнении со 2-й группой, \# - $p<0,05$ при сравнении с 3-й группой, \#\# - $<<0,01$ при сравнении с 3-й группой 
содержние БДНФ в тканях мозга было достоверно выше $(p<0,01)$. Также достоверно различалось содержание БДНФ в тканях мозга при введении БДНФ, сорбированного на НЧ с полоксамером, и без последнего $(p<0,05)$.

\section{ОБСУЖДЕНИЕ РЕЗУЛЬТАТОВ}

Проведенные исследования показали, что при внутривенном введении БДНФ, сорбированного на полилактидных НЧ, покрытых полоксамером 188, достоверно увеличивается

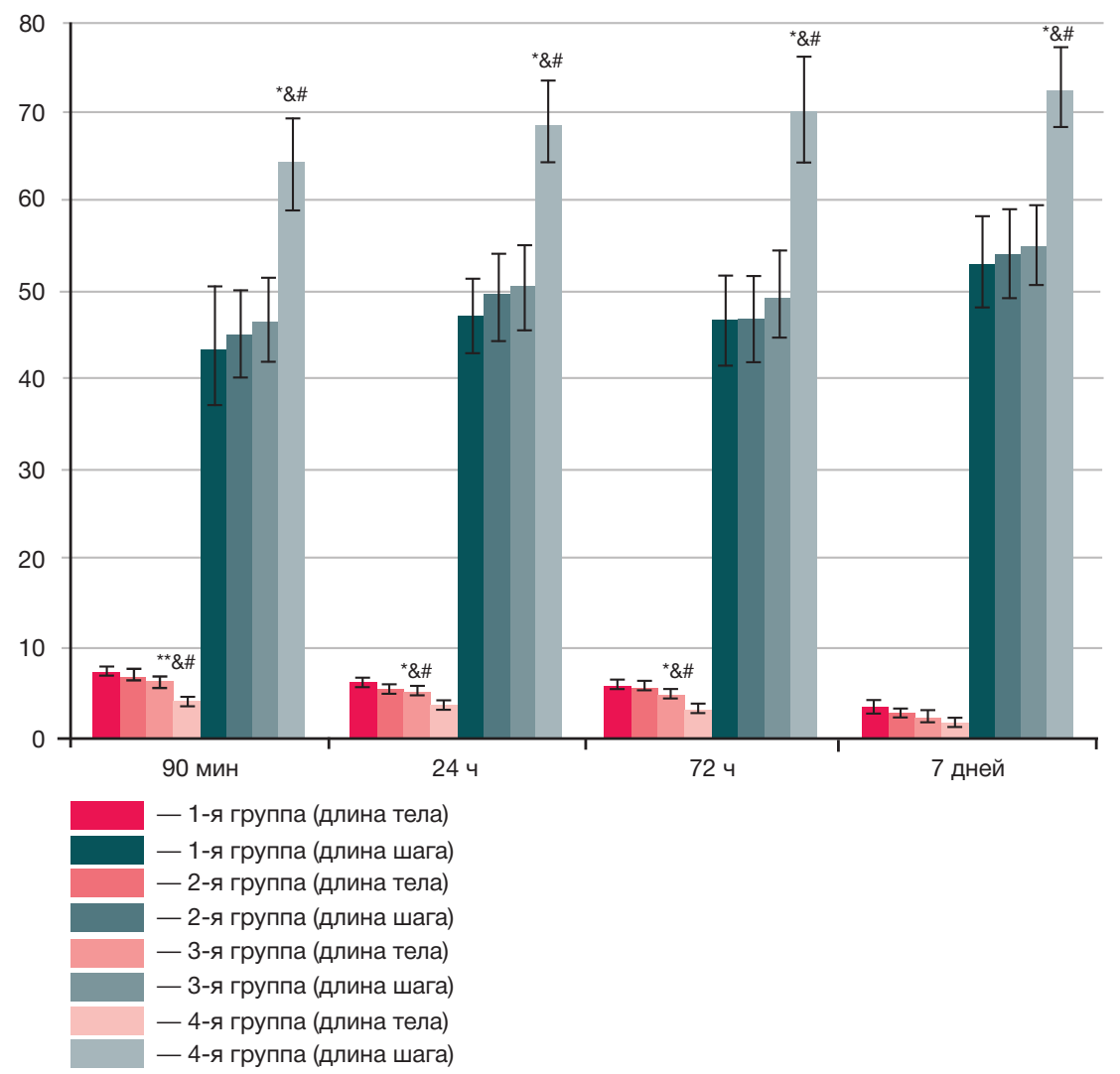

Рис. 2. Длина тела и шага у контрольных и экспериментальных мышей в модели паркинсонизма, мм (m $\pm \mathrm{SEM}) .{ }^{*}-p<0,05$ при сравнении с 1 -й группой, ** $-p<0,01$ при сравнении с 1-й группой, \& - $p<0,05$ при сравнении со 2-й группой, \&\& $-p<0,01$ при сравнении со 2-й группой, \# - $p<0,05$ при сравнении с 3-й группой, \#\# - $p<0,01$ при сравнении с 3-й группой

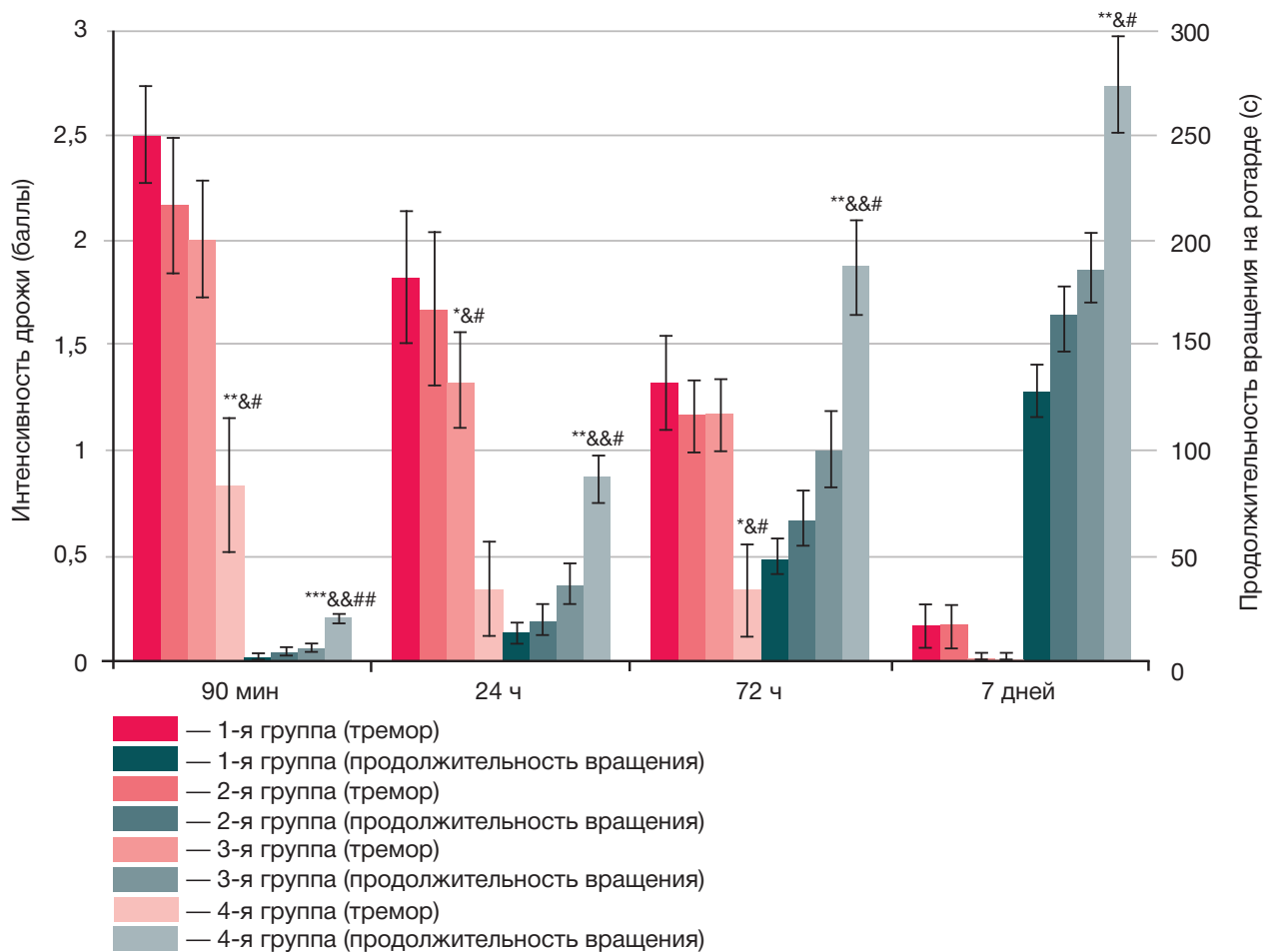

Рис. 3. Тремор (баллы) и продолжительность вращения на ротароде (с) у контрольных и экспериментальных мышей в модели паркинсонизма (m \pm SEM). * - $p<0,05$ при сравнении с 1-й группой, ** $-p<0,01$ при сравнении с 1-й группой, \& $-p<0,05$ при сравнении со 2-й группой, \&\& - $p<0,01$ при сравнении со 2-й группой, \#-p < 0,05 при сравнении с 3-й группой, \#\# - p<0,01 при сравнении с 3-й группой 
Таблица. Содержание БДНФ в тканях головного мозга после внутривенного введения различных форм БДНФ и физраствора мышам с паркинсонизмом (pg/mg, m+/-SE)

\begin{tabular}{|c|c|c|c|}
\hline 1 -я группа & 2-я группа & 3-я группа & 4-я группа \\
\hline $163,91 \pm 10,17$ & $184,03 \pm 2,28$ & $194,51 \pm 1,14^{\star} \# \#$ & $204,46 \pm 3,71^{\star \star} \# \# \&$ \\
\hline
\end{tabular}

Примечание: * - $p<0,05$ в сравнении с физраствором; ** $-p<0,01$ в сравнении с физраствором; \#\# - $p<0,01$ в сравнении с БДНФ; \& - $<<0,05$ в сравнении с БДНФ, сорбированном на НЧ.

его концентрация в головном мозге. Доставленный в головной мозг БДНФ способствует значительному уменьшению выраженности симптомов, возникших в модели паркинсонизма, вызванного МФТП. Системное введение раствора чистого БДНФ не оказывало значимого противопаркинсонического действия. Статистически достоверное уменьшение ригидности и нормализация локомоторной активности были отмечены только в группе животных, получавших БДНФ, сорбированный на покрытых полоксамером НЧ. Этот эффект можно было наблюдать, начиная с 45 мин после введения МФТП на протяжении 7 дней. Аналогично только в этой группе животных было отмечено влияние препарата на тремор, вызванный введением МФТП. Тенденция к увеличению/увеличение содержания БДНФ при введении раствора БДНФ может свидетельствовать о наличии транспортных систем в клетках ГЭБ.

Данные нашего исследования коррелируют с результатами, полученными при изучении направленного транспорта с помощью наноразмерных коллоидных частиц. В экспериментах с использованием полибутилцианоакрилатных НЧ, покрытых полисорбатом 80, была показана возможность доставки в головной мозг фрактора роста нервов (NGF). Последний уменьшал выраженность симптомов паркинсонизма, вызванных у мышей MPTP [9, 10].

В настоящее время активно исследуется активирующее влияние БДНФ на регенерацию нервной ткани. Показано, что инкубирование нервной ткани в среде, содержащей БДНФ, приводит к увеличению плотности синаптических контактов и увеличению выживаемости нейронов [11]. Кроме того, БДНФ увеличивает выделение ацетилхолина и глутамата синаптическими структурами периферической и ЦНС $[12,13]$. Эти медиаторы являются ключевыми в механизме функционирования экстрапирамидной системы и развития паркинсонизма. Как показали исследования ряда авторов, БДНФ стимулирует досраминергические нейроны [14]. В то же время непосредственное введение в мозг БДНФ уменьшало выраженность вызванных МФТП симптомов паркинсонизма [15].

Таким образом, можно предположить, что доставляемый с помощью НЧ в головной мозг БДНФ способен уменьшать выраженность симптомов вызванного МФТП паркинсонизма за счет прямой стимуляции выделения медиаторов и/или стимуляции регенераторной способности дофаминергических нейронов.

\section{ВЫВОДЫ}

Полученные результаты показали, что полилактидные НЧ, покрытые полоксамером 188, способны транспортировать БДНФ через ГЭБ, создавая в головном мозге его концентрацию, способную оказывать физиологическое действие.

\section{Литература}

1. Аляутдин Р. Н., Дешмух Р., Петров В. Е. Транспорт лекарственных веществ через гематоэнцесралический барьер. Вестник НИИ Молекулярной медицины. 2003; 11-29.

2. Lockman PR, Mumper RJ, Khan MA, Allen DD. Nanoparticle technology for drug delivery across blood-brain barrier. Drug Dev Ind Pharm. 2002; 28 (1): 1-13.

3. Begley DJ. Understanding and circumventing the blood-brain barrier. Acta Paediatr Suppl. 2003; (92): 83-91.

4. Lefauconneir JM. The blood brain barrier. J Physiological data. 1998; 140 (1): 3-13.

5. Alyautdin RN, Petrov VE, Kharkevich DA, Kreuter J. Passage of peptides across the blood-brain barrier with nanoparticles. Eur $\mathrm{J}$ Pharm Sci. 1994; (3): 91-2.

6. Bibel M, Barde Y. Neurotrophins: key regulator of cell fate and cell shape in the vertebrate nervous system. Genes Dev. 2000; (14): 2919-37.

7. Castellenos-Ortega MR, Cruz-Aguado R, Martinez-Marty L. Nerve growth factor: possibilities and limitations of its clinical application. Rev Neurol. 1999; 29 (5): 439-71.

8. Przedborski S, Jackson-Lewis V, Djaldetti R, Liberatore G, Vila M, Vukosavic S, Almer G. The parkinsonian toxin MPTP: action and mechanism. Restor Neurol Neurosci. 2000; 16 (2): 135-42.

9. Kreuter J. Nanoparticulate systems for brain delivery of drugs. Adv Drug Deliv Rev. 2001; (47): 65-81.

10. Kurakhmaeva K, Djindjikhashvili I, Petrov V, Balabanjan V, Voronina T,

Trofimov $S$ et al. Brain targeting of nerve growth factor using poly(butylcyanoacrilate) nanoparticles. J Drug Targ. 2009; (17): $564-74$.

11. Limongi T, Rocchi A, Cesca F, Tan H, Miele E, Giugni A. Delivery of Brain-Derived Neurotrophic Factor by 3D Biocompatible Polymeric Scaffolds for Neural Tissue Engineering and Neuronal Regeneration. Mol Neurobiol. 2018 Mar 29; DOI: 10.1007/ s12035-018-1022-z.

12. Tyler WJ, Perrett, Pozzo-Miller LD. The role of neurotrophins in neurotransmitter release. Neuroscience. 2002; (8): 524-31.

13. Schindowski K, Belarbi K, Buée L. Neurotrophic factors in Alzheimer's disease: role of axonal transport. Genes Brain Behav. 2008; (7): 43-56.

14. Bhurtel S, Katila N, Neupane S, Srivastav S, Park PH, Choi D. Methyleneblue protects dopaminergic neurons against MPTP-induced neurotoxicity by upregulating brain-derived neurotrophic factor. Ann N Y Acad Sci, 2018. DOI: 10.1111/ nyas.13870. Доступно по ссылке: https://www.ncbi.nlm.nih. gov/pubmed/29882218\#.

15. Chen JF, Wang M, Zhuang YH, Behnisch T. Intracerebroventricularlyadministered 1-methyl-4-phenylpyridinium ion and brain derived neurotrophic factor affect catecholaminergic nerve terminals and neurogenesis in the hippocampus, striatum and substantia nigra. Neural Regen Res. 2018; (13): 717-26. DOI: 10.4103/16735374.230300 . 


\section{References}

1. Alyautdin RN, Deshmukh R, Petrov VE. Transport lekarstvennykh veshchestv cherez gematoencephalicheskiy barier. Vestnik NII Molekulyarnoy meditsiny. 2003; 11-29.

2. Lockman PR, Mumper RJ, Khan MA, Allen DD. Nanoparticle technology for drug delivery across blood-brain barrier. Drug Dev Ind Pharm. 2002; 28 (1): 1-13.

3. Begley DJ. Understanding and circumventing the blood-brain barrier. Acta Paediatr Suppl. 2003; 92: 83-91.

4. Lefauconneir JM. The blood brain barrier. J Physiological Data. 1998; 140 (1): 3-13.

5. Alyautdin RN, Petrov VE, Kharkevich DA, Kreuter J. Passage of peptides across the blood-brain barrier with nanoparticles. Eur $\mathrm{J}$ Pharm Sci. 1994; (3): 91-2.

6. Bibel M, Barde Y. Neurotrophins: key regulator of cell fate and cell shape in the vertebrate nervous system. Genes Dev. 2000; (14): 2919-37.

7. Castellenos-Ortega MR, Cruz-Aguado R, Martinez-Marty L. Nerve growth factor: possibilities and limitations of its clinical application. Rev Neurol. 1999; 29 (5): 439-71.

8. Przedborski S, Jackson-Lewis V, Djaldetti R, Liberatore G, Vila M, Vukosavic S, Almer G. The parkinsonian toxin MPTP: action and mechanism. Restor Neurol Neurosci. 2000; 16 (2): 135-42.

9. Kreuter J. Nanoparticulate systems for brain delivery of drugs. Adv Drug Deliv Rev. 2001; (47): 65-81.

10. Kurakhmaeva K, Djindjikhashvili I, Petrov V, Balabanjan V, Voronina T,
Trofimov $S$ et al. Brain targeting of nerve growth factor using poly(butylcyanoacrilate) nanoparticles. J Drug Targ. 2009; (17): 564-74.

11. Limongi T, Rocchi A, Cesca F, Tan H, Miele E, Giugni A. Delivery of Brain-Derived Neurotrophic Factor by 3D Biocompatible Polymeric Scaffolds for Neural Tissue Engineering and Neuronal Regeneration. Mol Neurobiol. 2018 Mar 29. DOI: 10.1007/ s12035-018-1022-z.

12. Tyler WJ, Perrett, Pozzo-Miller LD. The role of neurotrophins in neurotransmitter release. Neuroscience. 2002; (8): 524-31.

13. Schindowski K, Belarbi K, Buée L. Neurotrophic factors in Alzheimer's disease: role of axonal transport. Genes Brain Behav. 2008; (7): 43-56.

14. Bhurtel S, Katila N, Neupane S, Srivastav S, Park PH, Choi D. Methyleneblue protects dopaminergic neurons against MPTPinduced neurotoxicity by upregulating brain-derived neurotrophic factor. Ann N Y Acad Sci. 2018.DOI: 10.1111/nyas.13870. Available at: https://www.ncbi.nlm.nih.gov/pubmed/29882218\#.

15. Chen JF, Wang M, Zhuang YH, Behnisch T. Intracerebroventricularlyadministered 1-methyl-4-phenylpyridinium ion and brain derived neurotrophic factor affect catecholaminergic nerve terminals and neurogenesis in the hippocampus, striatum and substantia nigra. Neural Regen Res. 2018; (13): 717-26. DOI: 10.4103/16735374.230300. 